\section{Somatic Embryogenesis and Plant Regeneration from in-vitro-grown Leaf Explants of Rose}

\author{
C.K. Kim and J.Y. Oh \\ Department of Horticulture, Sangju National University, Sangju 742-711, Korea
}

J.D. Chung

Department of Horticulture, Kyungpook National University, Daegu 702-701, Korea

A.M. Burrell and D.H. Byrne ${ }^{1}$

Department of Horticultural Sciences, Texas A\&M University, College Station, TX 77843-2113

\section{Additional index words. Rosa, callus, silver nitrate}

Abstract. Somatic embryogenesis was initiated from in vitro-grown leaf explants of rose using an induction period of 4 weeks on MS basal medium supplemented with auxin followed by several subcultures on MS basal medium with cytokinin. ' $4^{\text {th }}$ of July' showed the highest regeneration frequency $(\mathbf{2 4 . 4 \%})$ on $5.3 \mu \mathrm{M}$ NAA followed by culture on medium containing 18.2 $\mu$ м zeatin. 'Tournament of Roses' produced somatic embryos when cultured for 4 weeks on medium containing dicamba, $2.3 \mu \mathrm{M}$ followed by three subcultures on medium containing 18.2 $\mu \mathrm{m}$ zeatin. Embryogenic callus matured on MS media containing $0.5 \mu \mathrm{M}$ NAA, $6.8 \mu \mathrm{m}$ zeatin, and $2.9 \mu \mathrm{M} \mathrm{GA}_{3}$. Long-term cultures were established for both cultivars. Somatic embryos germinated on MS medium containing IBA and BA. Silver nitrate $(58.8 \mu \mathrm{M})$ enhanced shoot formation and germination of somatic embryos. Plants derived from somatic embryos were acclimatized and successfully established in the greenhouse.

Rose is one of the most economically important flowers worldwide. Genetic improvement of rose through conventional breeding is limited by several factors such as polyploidy and the highly heterozygous nature of existing cultivars. Genetic engineering based on tissue culture technology provides an option for overcoming these restrictions. Although the establishment of somatic embryogenesis can provide target material for genetic manipulations and also for the clonal propagation of plants in vitro, the mechanisms involved in embryogenic callus induction and differentiation are still poorly understood.

In roses, somatic embryogenesis has been obtained from a variety of explants such as calli derived from leaf tissue (De Wit et al., 1990), immature leaf and stem segments (Rout et al., 1991), immature seeds (Kunitake et al., 1993), petioles, roots (Marchant et al., 1996; Roberts et al., 1995), and anther filaments (Noriega and Sondahl, 1991). According to published reports, callus initiation from rose tissues required the presence of an auxin (mainly 2,4-dichorophenoxy acetic acid (2,4-D) and $\alpha$-naphthalene acetic acid (NAA)) in the culture

Received for publication 30 June 2003. Accepted for publication 28 Dec. 2003. Research conducted at the Department of Horticultural Sciences, Texas A\&M University, College Station, TX . This work was supported by the postdoctoral fellowship program from Korea Science \& Engineering Foundation (KOSEF) and the Robert Basye Endowment in Rose Breeding and Genetics. ${ }^{1}$ To whom reprint requests should be addressed; e-mail d-byrne@tamu.edu. medium. Other strong auxins such as dicamba (Murali et al., 1996) and picloram (Kintzios et al., 1999) have been used. Preincubation on a high 2,4-D concentration increased the frequency of embryogenesis (Hsia and Korban 1996; Marchant et al., 1996). The transfer of embryogenic callus to a medium with reduced levels or no auxin results in the maturation of somatic embryos and regeneration of plants.

One critical point in the regeneration of the rose via somatic embryogenesis is the further development and germination of the embryo (Dohm et al., 2001). Omission or lowering the concentration of 2,4-D in the culture medium encouraged embryo development and germination in many cultivars of Rosa species (Matthews et al., 1991; Roberts et al., 1990). Roberts et al. (1995) also reported that chilling at $4{ }^{\circ} \mathrm{C}$ for 2 weeks improved the germination rates from $12 \%$ to $24 \%$. The combination of 6-benzyladenine (BA) with methyl laurate was observed to stimulate somatic embryo development in the cultivar Vague (Sarasan et al., 2001). It has been demonstrated that periods of stress during tissue culture, such as desiccation (Lee at al., 2001) and cold (Marchant et al., 1996), may increase the number of viable embryos for carrot and rose, respectively. Application of silver nitrate has been also reported to promote somatic embryogenesis of spinach (Ishizaki et al., 2000). In this report we describe a protocol starting with in vitrogrown rose tissue for regeneration via somatic embryogenesis that succeeded for two of the five genotypes tested. In addition, the influence of silver nitrate on the germination of somatic embryos was tested.
Plantmaterials. Four commercial rose cultivars (Rosa hybrida '4 th $^{\text {th }}$ of July', 'Tournament of Roses', 'Graham Thomas', and 'Sequoia Ruby') and one rose species ( $R$. multiflora Thunb.) were used in this study. Shoot cultures were established through axillary bud proliferation on a Murashige and Skoog (MS) basal medium (Murashige and Skoog, 1962) containing $2.2 \mu \mathrm{mBA}$ (Sigma B3408), $30 \mathrm{~g} \cdot \mathrm{L}^{-1}$ sucrose and $7 \mathrm{~g} \cdot \mathrm{L}^{-1}$ agar (Sigma A1296). All basal media containing $30 \mathrm{~g} \cdot \mathrm{L}^{-1}$ sucrose were adjusted to $\mathrm{pH} 5.8 \pm 0.1$ with $1 \mathrm{n} \mathrm{NaOH}$ or 1 $\mathrm{n} \mathrm{HCl}$ before autoclaving. Every 4 weeks, the shoot clusters were divided into single shoots and transferred onto fresh medium. For the regeneration experiment, fully developed leaf explants were harvested from 4-week-old cultures. Shoot cultures were incubated under a 16-h photoperiod [cool white fluorescent lamps $\left.\left(90 \mu \mathrm{mol} \cdot \mathrm{m}^{-2} \cdot \mathrm{s}^{-1}\right)\right]$ at $21 \pm 2{ }^{\circ} \mathrm{C}$. Each treatment for callus induction and somatic embryogenesis induction was replicated five times, and each replication consisted of a single petri dish containing nine explants.

Callus induction. Leaf segments $(0.5 \mathrm{~cm}$ long) were excised and placed with the adaxial side down on MS basal medium solidified with $0.24 \%$ Gelrite (Sigma G1910) and supplemented with either $2,4-\mathrm{D}$ at $0.5,2.3,4.5$, or $9.0 \mu \mathrm{m}$, NAA at $0.5,2.7,5.5$, or $10.7 \mu \mathrm{m}$, or dicamba at 0.5 , $2.3,4.5$, or $9.0 \mu$ mrespectively for callus induction. Media $\mathrm{pH}$ was adjusted to $5.8 \pm 0.1 \mathrm{using}$ $1 \mathrm{n} \mathrm{NaOH}$ or $1 \mathrm{n} \mathrm{HCl}$. Media were sterilized by autoclaving at $121^{\circ} \mathrm{C}$ for $20 \mathrm{~min}$, allowed to cool, and dispensed into sterile polystyrene $100 \times 15-\mathrm{mm}$ petri dishes $(25 \mathrm{~mL}$ of medium per dish, nine explants per dish). Cultures were incubated for 4 weeks at $25^{\circ} \mathrm{C}$ under a $16-\mathrm{h}$ photoperiod provided by cool white fluorescent lamps (40 to $50 \mu \mathrm{mol} \cdot \mathrm{m}^{-2} \cdot \mathrm{s}^{-1}$ ) or under dark conditions. Each treatment for callus induction was replicated three times, and each replication was a single petri dish containing nine explants. Data on the number of explants developing callus were recorded.

Induction of somatic embryogenesis. After 4 weeks, explants were transferred to MS basal medium containing different concentrations of either BA ( 4.4 or $8.8 \mu \mathrm{m})$ or zeatin $(9.1$ or 18.2 $\mu \mathrm{m})$. Leaf explants were then transferred to fresh medium every 4 weeks. Tissue proliferation was encouraged by transferring embryogenic clusters ( $5 \mathrm{~mm}$ in diameter) to MS basal media containing $0.5 \mu \mathrm{mNAA}, 6.8 \mu$ mzeatin and 2.9 $\mu$ mgibberellic acid $\left(\mathrm{GA}_{3}\right)($ Sigma G7645) at 25 ${ }^{\circ} \mathrm{C}$ under a $16 \mathrm{~h}$ photoperiod provided by cool white fluorescent lamps (40 to $50 \mu \mathrm{mol} \cdot \mathrm{m}^{-2} \cdot \mathrm{s}^{-1}$ ). Zeatin and $\mathrm{GA}_{3}$ were added before autoclaving whereas the other hormones were added after autoclaving. Data on the number of explants developing somatic embryos were recorded.

Histology. For histological observation, somatic embryos were fixed in 5 formalin: 5 glacial acetic acid: 90 ethanol (by volume) for $48 \mathrm{~h}$, dehydrated through a graded ethanol-xylol series and embedded in paraffin wax. Tissue was sectioned into 14- $\mu \mathrm{m}$-thick slices, stained with $0.05 \%(\mathrm{w} / \mathrm{v})$ toluidine blue, and examined under a microscope (Nikon, Japan). 
Table 1. Plant growth regulator effects on callus induction and somatic embryogenesis of leaf explants of rose.

\begin{tabular}{|c|c|c|c|}
\hline $\begin{array}{l}\text { Treatment }^{\mathrm{z}} \\
(\mu \mathrm{M})\end{array}$ & $\begin{array}{l}\text { Responding } \\
\text { cultivar }\end{array}$ & $\begin{array}{c}\text { Callus } \\
\text { induction } \\
(\%)\end{array}$ & $\begin{array}{c}\text { Somatic } \\
\text { embryogenesis }^{\mathrm{x}} \\
(\%)\end{array}$ \\
\hline \multirow[t]{2}{*}{ 2,4-D 2.3/zeatin 9.1 } & $4^{\text {th }}$ of July & $100 a^{w}$ & $6.6 \mathrm{~d}$ \\
\hline & Tournament of Roses & $100 \mathrm{a}$ & $0 \mathrm{e}$ \\
\hline \multirow[t]{5}{*}{ 2,4-D 4.5/zeatin 18.2} & $4^{\text {th }}$ of July & $100 \mathrm{a}$ & $24.4 \mathrm{a}$ \\
\hline & Tournament of Roses & $100 \mathrm{a}$ & $0 \mathrm{e}$ \\
\hline & Graham Thomas & $88.8 \mathrm{bc}$ & $0 \mathrm{e}$ \\
\hline & Sequoia Ruby & $93.3 \mathrm{~b}$ & $0 \mathrm{e}$ \\
\hline & R. multiflora & $55.5 \mathrm{~d}$ & $0 \mathrm{e}$ \\
\hline \multirow[t]{3}{*}{ NAA 5.5/zeatin 18.2} & $4^{\text {th }}$ of July & $100 \mathrm{a}$ & $17.7 \mathrm{bc}$ \\
\hline & Tournament of Roses & $100 \mathrm{a}$ & $0 \mathrm{e}$ \\
\hline & Sequoia Ruby & $84.4 \mathrm{c}$ & $0 \mathrm{e}$ \\
\hline \multirow[t]{2}{*}{ Dicamba 2.3/zeatin 18.2} & $4^{\text {th }}$ of July & $100 \mathrm{a}$ & $0 \mathrm{e}$ \\
\hline & Tournament of Roses & $100 \mathrm{a}$ & $13.3 \mathrm{c}$ \\
\hline
\end{tabular}

${ }^{\mathrm{z}}$ Auxin/cytokinin, leaf explants were precultured on MS medium supplemented with the indicated auxin $[2,4 \mathrm{D}(0.5,2.3,4.5,9.0 \mu \mathrm{M})$, NAA $(0.5,2.7,5.5,10.7 \mu \mathrm{M})$ or dicamba $(0.5,2.3,4.5,9.0 \mu \mathrm{M})]$ for 4 weeks followed by several re-culture periods on MS basal medium containing the same auxin with the indicated cytokinin [BA $(4.4$ or $8.8 \mu \mathrm{M})$ or zeatin $(9.1$ or $18.2 \mu \mathrm{M})]$. The varieties tested were ' $4^{\text {th }}$ of July', 'Tournament of Roses', 'Graham Thomas', 'Sequoia Ruby', and R. multiflora. Only the treatments that had a positive reaction are shown. The rest of the treatments did not form callus or somatic embryos.

${ }^{y}$ Callus fresh weight per explant $>10 \mathrm{mg}$ was recorded.

${ }^{x}$ Data was collected 14 weeks after culture initiation.

"Mean separation in columns by Duncan's multiple range test. Means within a column followed by the same letter are not significantly different at $5 \%$ level.

Embryogerminationandrecoveryof plants. To examine the effect of silver nitrate on germination of somatic embryos, 50 randomly selected cotyledonary-stage embryos per petri dish (three petri dishes per treatment) were cultured on MS basal medium supplemented with $3 \%$ sucrose, $0.5 \mu \mathrm{m}$ indole-3-butyric acid (IBA) (Sigma I5386) and $9.8 \mu \mathrm{mBA}$ at 4 levels of silver nitrate $(0.0,5.9,58.8$, or 176.6 $\mu \mathrm{m})$ which was filter sterilized. Rooting was induced by subculturing embryos onto MS basal medium containing NAA at $0.2 \mu \mathrm{m}$ Regenerating somatic embryos were incubated at $25^{\circ} \mathrm{C}$ under a 16 -h photoperiod as mentioned above. For greenhouse acclimatization, rooted shoots and germinated embryos were grown in pots containing Sunshine Mix No. 4 (SunGro Horticulture). Potted plants were covered with polyethylene bags for 2 to 3 weeks, that were progressively opened to adapt the plants to a lower humidity. The number of embryos that germinated into plants were recorded.

\section{Results and Discussion}

Induction of callus. Leaf explants developed callus at cut surfaces 7 to $10 \mathrm{~d}$ after initial culture. Leaf explants cultured on MS basal medium at the lowest concentration $(0.5 \mu \mathrm{m})$ of either 2,4-D, NAA, or dicamba produced little callus, whereas up to $100 \%$ of the leaf explants produced callus when cultured on MS basal medium containing either 2,4-D, NAA, or dicamba at $9.0,10.7$, or $9.0 \mu \mathrm{m}$, respectively. Callus morphology differed with the auxin treatment. Callus produced on media containing 2,4-D tended to be grayish-white with various degrees of friability. A higher concentration of 2,4-D $(9.0 \mu \mathrm{m})$ resulted in extremely friable and watery callus. However, callus produced on media containing NAA was less friable than that of 2,4-D treatments. Leaf explants cultured on MS basal media containing dicamba produced callus with primarily small, single cells and very small cell clumps.
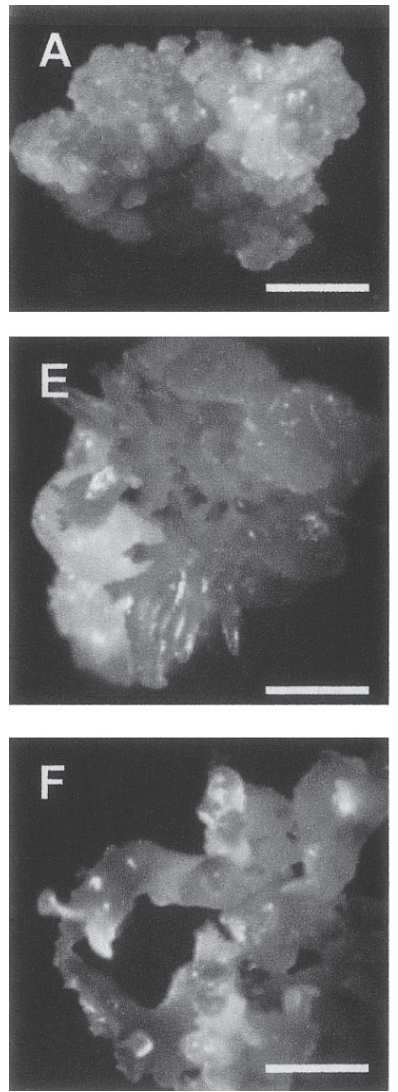

treatments tested. The callus cultured under a 16-h photoperiod provided by cool white fluorescent lamps (40 to $50 \mu \mathrm{mol} \cdot \mathrm{m}^{-2} \cdot \mathrm{s}^{-1}$ ) was initially hard and compact in appearance with pale yellow-white or green coloration and grew slowly. Callus cultured under dark conditions was less compact and reddish-brown. However, there was no difference in the number of developing somatic embryos.

Induction and proliferation of somatic embryogenesis. After 4 weeks on callus induction medium, explants were subcultured on MS basal medium containing zeatin or BA for induction of somatic embryogenesis. About 3 weeks after transfer onto MS basal medium containing 9.1 or $18.2 \mu$ mzeatin, somatic embryo formation was observed and the process continued for about three subculture cycles (12 weeks). Embryogenesis was not observed with any of the 2,4D/BA, NAA/BA or dicamba/BA combinations. Secondary somatic embryogenesis, cotyledonary-stage embryos and embryogenic callus proliferation were observed during subsequent subcultures. Secondary somatic embryogenesis was observed in rose by Rout et al. (1991) and Hsia and Korban (1996). Li et al. (2002) obtained a 36\% frequency of secondary somatic embryogenesis on leaf sections of 'Carefree Beauty' incubated on a medium containing $3.8 \mu \mathrm{mol} \cdot \mathrm{L}^{-1} \mathrm{ABA}$ for $>1$ year. The cultivar ' $4^{\text {th }}$ of July' showed the
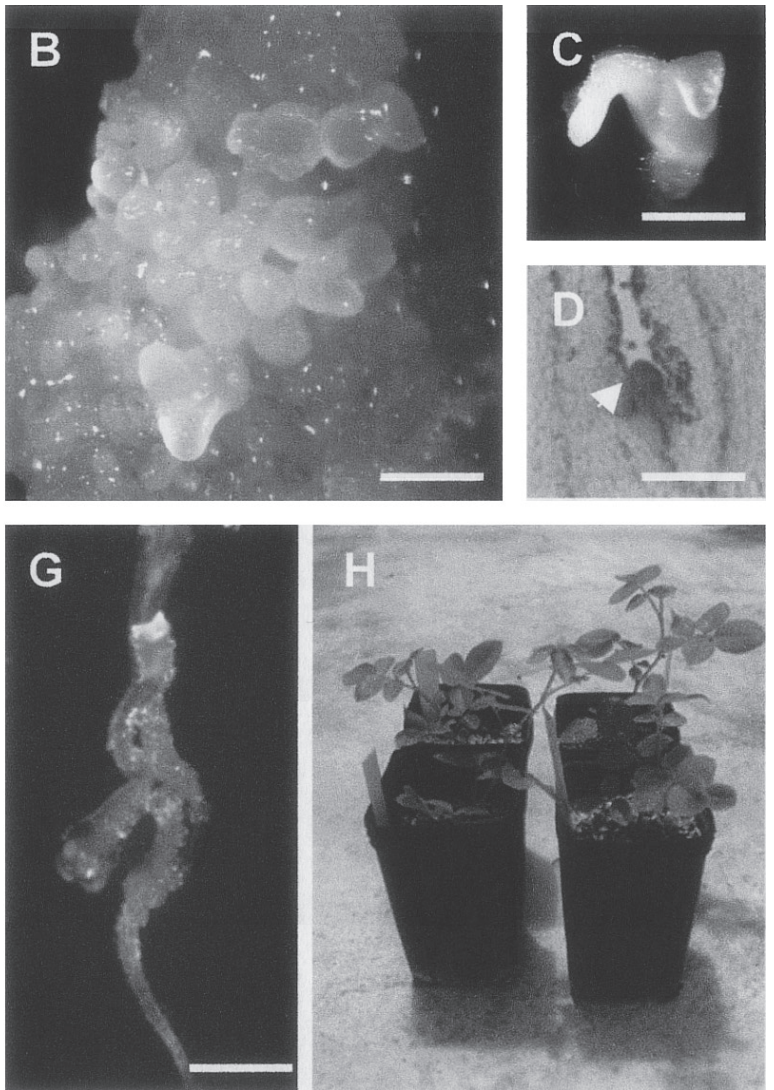

Fig. 1. Plant regeneration from rose ' 4 th of July' via somatic embryogenesis. (A) Embryogenic callus derived from an in vitro grown leaf explant after 4 months in culture (bar $0.5 \mathrm{~mm}$ ). (B) Globular- and heart-stage embryos on embryogenic callus (bar $0.5 \mathrm{~mm}$ ). (C) Well developed cotyledonary-stage somatic embryo (bar $0.7 \mathrm{~mm}$ ). (D) Longitudinal section of somatic embryo showing meristem (arrowhead) (bar $0.1 \mathrm{~mm}$ ). (E) Elongation of embryos on MS basal medium containing 0.2 $\mu \mathrm{M}$ IBA, 2.2 $\mu \mathrm{M}$ BA and 16.9 $\mu \mathrm{M}$ silver nitrate (bar $1 \mathrm{~mm}$ ). (F) Germination of somatic embryo (bar $2 \mathrm{~mm}$ ). (G) Germinated somatic embryo (bar $4 \mathrm{~mm}$ ). (H) Phenotypically normal somatic embryo derived plants of rose ' $4^{\text {th }}$ of July'. 
Table 2. Effect of silver nitrate on the germination of in vitro grown leaf derived somatic embryos of rose cvs. $4^{\text {th }}$ of July and Tournament of Roses.

\begin{tabular}{|c|c|c|}
\hline \multirow{2}{*}{$\begin{array}{l}\text { Silver } \\
\text { nitrate } \\
(\mu \mathrm{M})\end{array}$} & \multicolumn{2}{|c|}{ Germination $^{\mathrm{z}}(\%)$} \\
\hline & $4^{\text {th }}$ of July & Tournament of Roses \\
\hline$\overline{0}$ & $25 \pm 3.2 b^{y}$ & $19 \pm 2.9 \mathrm{c}$ \\
\hline 5.9 & $27 \pm 4.7 b$ & $21 \pm 3.4 b c$ \\
\hline 58.8 & $39 \pm 6.7 \mathrm{a}$ & $28 \pm 7.9 \mathrm{a}$ \\
\hline 176.6 & $26 \pm 4.6 b$ & $24 \pm 3.9 \mathrm{ab}$ \\
\hline
\end{tabular}

${ }^{\text {zPercent }}$ germination was determined 4 weeks after transfer to embryo germination medium (MS basal medium with $0.2 \mu \mathrm{M}$ IBA, $2.2 \mu \mathrm{M}$ BA and 3\% sucrose). Fifty embryos were used per replication. Mean $\pm \operatorname{SE}(n=3)$. Embryogenic callus of ' $4^{\text {th }}$ of July', and 'Tournament of Roses' cultured on MS basal medium with $0.2 \mu \mathrm{M} 2,4-\mathrm{D}$, or $1.1 \mu \mathrm{M}$ dicamba for 4 weeks, respectively, following a subculture on MS basal medium with $8.7 \mu \mathrm{m}$ zeatin.

${ }^{y}$ Mean separation in columns by Duncan's multiple range test. Means within a column followed by the same letter are not significantly different at the $5 \%$ level.

highest regeneration frequency on MS basal medium containing $4.5 \mu \mathrm{m} 2,4-\mathrm{D}$ followed by culture on MS basal medium containing 18.2 umzeatin. In contrast, 'Tournament of Roses' produced somatic embryos when cultured for 4 weeks on medium containing $2.3 \mu$ mdicamba and for three further culture periods on 18.2 $\mu$ mzeatin. Only two (' $4^{\text {th }}$ of July' and 'Tournament of Roses') of the five genotypes tested produced somatic embryos (Table 1). After the transfer of embryogenic clusters (mixture of globular embryos and regenerating embryos) onto MS medium, the clusters developed into a mixture of smooth embryogenic callus tissue, more matured embryos and hard green callus tissue as previously described by Noriega and Sondahl (1991). Embryogenic callus was separated from the more matured embryos and hard green callus tissue with 2 to 3 subcultures over 8 to 12 weeks to develop lines consisting of just embryogenic callus. Although in a previous study, somatic embryogenic callus was initiated from adventitious roots of $R$. multiflora (data not shown), it was not initiated from in vitro-grown leaf explants in any of the treatments tested. The callus from $R$. multiflora roots, which was compact, friable, and paler in color than the rest was best for somatic embryogenesis. However, both the texture and color of callus derived from adventitious roots at various concentrations of 2,4-D were quite different.

As previously reported (Dohm et al., 2001; Hsia and Korban, 1996) callus was induced from leaf explants of 'Carefree Beauty' and 'Heckenzauber' with both auxin alone and in combination with cytokinin, whereas in this study somatic embryogenesis was induced only when MS basal medium with auxins alone was used for the first 4 weeks of the callus induction period. In contrast Noriega and Sondahl (1991) and Kintzios et al. (1999) reported that an auxin and cytokinin combination was essential for the induction of embryogenic callus in rose tissue from 'Royalty' and 'Soraya'.

Genotype was a significant factor influ- encing explant embryogenic differentiation in culture, since only two of five investigated cultivars produced somatic embryogenesis. A similar genotypic response to somatic embryogenesis among $R$. hybrida cultivars has been reported (De Wit et al., 1990; Hsia and Korban, 1996).

Maturation and germination of somatic embryos. Cotyledonary-stage somatic embryos appeared 1 to 2 weeks after globular and heartshaped embryos had been subcultured on MS basal medium with $0.5 \mu \mathrm{m}$ IBA, $9.8 \mu \mathrm{mBA}$, and $3 \%$ sucrose. Most embryos were morphologically normal (Fig. 1D). Morphologically abnormal embryos failed to germinate. Silver nitrate $(58.8 \mu \mathrm{m})$ in MS basal medium promoted embryo germination by greening the embryos (Table 2, Fig. 1E) for both cultivars. Germination was preceded by further elongation of the cotyledons (Fig. 1F). Roots and shoots developed further when somatic embryos were transferred to MS basal medium containing a low concentration of NAA $(0.5 \mu \mathrm{m})$ (Fig. $1 \mathrm{G})$. Whole regenerated plants bearing three or four leaves were potted and acclimatized to greenhouse conditions with greater than $90 \%$ survival. All plants were phenotypically normal (Fig. 1H).

The beneficial effect of BA (alone or combined with IAA or IBA) on somatic embryo maturation from rose explants (Marchant et al., 1996) and of kinetin on rose embryogenesis (Kunitake et al., 1993) have been previously documented with other rose genotypes. One critical stage in regeneration of rose via somatic embryogenesis is continued development and germination of the embryo (Dohm et al., 2001). Although silver nitrate has been used extensively in various plant species to induce somatic embryogenesis (Ishizaki et al., 2000; Kong and Yeung, 1994), we believe this is the first report that this ethylene inhibitor is an effective promoter of somatic embryo germination of rose. Dubois and de Vries (1995) found that the addition of silver nitrate promoted both the regenerative capacity and the time of adventitious bud emergence from leaf explants of glasshouse grown cut rose 'Madelon', 'Only Love', 'Presto', 'Sonia', and 'Tineke'.

Using in vitro-grown leaf explants from five genotypes of rose, a protocol for induction, maturation and germination of somatic embryos was developed. Somatic embryogenesis was initiated and maintained in two of the five genotypes investigated, demonstrating a genotype specificity that is known to occur in other protocols for the induction of somatic embryogenesis. The addition of silver nitrate in the medium increased the germination of the somatic embryos in the two genotypes that responded to the treatments.

\section{Literature Cited}

De Wit, J.C., H.F. Esendam, J.J. Horkanen, and U. Tuominen. 1990. Somatic embryogenesis and regeneration of flowering plants in rose. Plant Cell Rpt. 6:73-77.
Dohm, A., C. Ludwig, K. Nehring, and T. Debener. 2001. Somatic embryogenesis in roses. Acta Hort. 547:341-347.

Dubois, L. and D. deVries. 1995. Preliminary report on the direct regeneration of adventitious buds on leaf explants of in vitro grown glass house rose cultivars. Gartenbauwissenschaft 60:249-253.

Hsia, C.N. and S.S. Korban. 1996. Organogenesis and somatic embryogenesis in callus cultures of Rosa hybrida and Rosa chinensis Minima. Plant Cell Tissue Org. Cult. 44:1-6.

Ishizaki, T., F. Komai, and K. Msuda. 2000. Exogenous ethylene enhances formation of embryogenic callus and inhibits embryogenesis in cultures of explants of spinach roots. J. Amer. Soc. Hort. Sci. 125:21-24.

Kintzios, S., C. Manos, and O. Makri. 1999. Somatic embryogenesis from mature leaves of rose (Rosa sp.). Plant Cell Rpt. 18:467-472.

Kong, L. and E.C. Yeung . 1994. Effects of ethylene and ethylene inhibitors on white spruce somatic embryo maturation. Plant Sci. 104:71-80.

Kunitake, H., H. Imamizo, and H. Mii. 1993. Somatic embryogenesis and plant regeneration from immature seed-derived calli of rugosa rose (Rosa rugosa Thumb.). Plant Sci. 90:187-194.

Lee, E.K., D.Y. Cho, and W.Y. Soh. 2001. Enhanced production and germination of somatic embryos by temporary starvation in tissue cultures of Daucus carota. Plant Cell Rpt. 20:408-415.

Li, X., S.F. Krasnyanski, and S.S. Korban. 2002. Somatic embryogenesis, secondary somatic embryogenesis, and shoot organogenesis in Rosa. J. Plant Physiol. 159:313-319.

Marchant, R., M.R. Davey, J.A. Lucas, and J.B. Power. 1996. Somatic embryogenesis and plant regeneration in floribunda rose (Rosa hybrida L. cvs Trumpeter and Glad Tidings). Plant Sci. 120:95-105.

Matthews, D., J. Mottley, K. Yokoya, and A. V. Roberts. 1991. Regeneration of plants from protoplasts of Rosa species (Roses), p. 146-160. In: Y.P.S. Bajaj (eds.). Biotechnology in Agriculture and Forestry (Plant protoplasts and Genetic Engineering). vol. 29. Springer, Heidelberg.

Murali, S., D. Sreedhar, and T.S. Lokeswari. 1996. Regeneration through somatic embryogenesis from petal-derived calli of Rosa hybrida L. cv Arizona (hybrid tea). Euphytica 91:271-275.

Murashige, T. and F.A. Skoog. 1962. Revised medium for rapid growth and bioassays with tobacco tissue cultures. Physiol. Plant 15:473-497.

Noriega, C. and M.R. Sondahl. 1991. Somatic embryogenesis in hybrid tea roses. Biotechnology 9:991-993.

Roberts, A.V., I. Horan, D. Mathews, and J. Mottley. 1990. Protoplast technology and somatic embryogenesis in Rosa, p. 110-115. In: J. de Jong (ed.). Proc. Eucarpia Symposium Integration of in vitro Techniques in Ornamental Plant Breeding. Center for Plant Breeding Research, AA Wageningen, 10-14 November, The Netherlands.

Roberts, A.V., K. Yokoya, S. Walker, and J. Mottley. 1995. Somatic embryogenesis in Rosa spp., p. 227-289. In: S. Jain, P. Gupta, and R. Newton (eds.). Somatic embryogenesis in woody plants. vol. 2. Kluwer, The Netherlands.

Rout, G.R., B.K. Debata, and P. Das. 1991. Somatic embryogenesis in callus cultures of Rosa hybrida cv. Landora. Plant Cell Tissue Org. Cult. 27:65-69.

Sarasan, V., A.V. Roberts, and G.R. Rout. 2001 Methyl laurate and 6-benzyladenine promote the germination of somatic embryos of a hybrid rose. Plant Cell Rpt. 20:183-186. 